\title{
Dynamic behaviour and shock-induced martensite transformation in near-beta Ti-5553 alloy under high strain rate loading
}

\author{
Lin Wang ${ }^{1,2, a}$, Yangwei Wang ${ }^{1,2},{\mathrm{Xin} \mathrm{Xu}^{1} \text {, and Chengze Liu }}^{1}$ \\ ${ }^{1}$ School of Materials Science and Engineering, Beijing Institute of Technology, 100081 Beijing, China \\ 2 National Key Lab of Science and Technology on Materials under Shock and Impact, Beijing Institute of Technology, \\ 100081 Beijing, China
}

\begin{abstract}
Ti-5553 alloy is a near-beta titanium alloy with high strength and high fracture toughness. In this paper, the dynamic behaviour and shock-induced martensite phase transformation of Ti-5553 alloy with alpha/beta phases were investigated. Split Hopkinson Pressure Bar was employed to investigate the dynamic properties. Microstructure evolutions were characterized by Scanning Electronic Microscopy and Transmission Electron Microscope. The experimental results have demonstrated that Ti-5553 alloy with alpha/beta phases exhibits various strain rate hardening effects, both failure through adiabatic shear band. Ti-5553 alloy with Widmannstatten microstructure exhibit more obvious strain rate hardening effect, lower critical strain rate for ASB nucleation, compared with the alloy with Bimodal microstructures. Under dynamic compression, shock-induced beta to alpha" martensite transformation occurs.
\end{abstract}

\section{Introduction}

Ti-5553 (Ti-5Al-5Mo-5V-3Cr) alloy is a near-beta titanium alloy with wide applications in aerospace industry due to its high strength and high fracture toughness $[1,2]$. The alloy is metastable and near-beta type as its molybdenum equivalent is about $10.5 \%$, which indicates beta matrix phase is unstable and easy to transform to various alpha phases under different heat treatments or loading conditions. Till now, the effects of heat treatment procedures on the static mechanical properties and fatigue properties of Ti-5553 alloy have been widely investigated [3-5]. The researches on the titanium alloy have shown that alpha/beta microstructures and their contents induce various mechanical properties, similar with other titanium alloys. Such phase transformations as $\beta \rightarrow \alpha, \beta \rightarrow \alpha^{\prime}$ or $\beta \rightarrow \alpha^{\prime \prime}$ usually occur under the mentioned loading conditions [6-8].

The dynamic properties of Ti-5553 alloy and other near-beta alloys have also been studied in recent years because of their potential applications in impact loading conditions [9-12]. The researches have demonstrated that adiabatic shear band is easy to occur in Ti-5553 alloy, similar with other titanium alloys. Also, in other metastable near-beta $\mathrm{Ti}$ alloy, such as TB10, when in pure beta phase condition, the occurrence of shockinduced martensite (SIM) phase transformation of $\beta \rightarrow \alpha^{\prime \prime}$ prohibits the occurrence of ASB [9]. However, due to different compositions and microstructures of metastable near-beta titanium alloys, the relationships among dynamic properties, ASB and SIM transformation have not been well understood yet. Also, for Ti-5553 alloy, the research about SIM transformation has not been reported. These

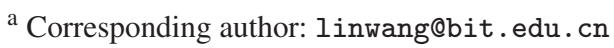

situations limit the further applications of Ti-5553 alloy and the like near-beta titanium alloy in high strain rate loading environment. Therefore, in this paper, the dynamic behaviours of Ti-5553 alloy with Bimodal and Widmannstatten microstructures were investigated. Adiabatic shear band and SIM transformation and their tentative correlation were discussed.

\section{Experimental procedures}

Ti-55531 (Ti-5Al-5Mo-5V-3Cr-1Fe) alloy is chosen as the experimental material. The transformation temperature of beta phase to alpha phase is $814^{\circ} \mathrm{C}$. The heat treatment is as follows: (1) $770^{\circ} \mathrm{C} / 3 \mathrm{~h} / \mathrm{AC}+600^{\circ} \mathrm{C} / 3 \mathrm{~h} / \mathrm{AC}$, Bimodal structure obtained and labelled as TL. (2) $850^{\circ} \mathrm{C} / 3 \mathrm{~h} / \mathrm{AC}+$ $600^{\circ} \mathrm{C} / 3 \mathrm{~h} / \mathrm{AC}$, Widmannstatten structure obtained and labelled as TA.

The static mechanical properties of Ti-5553 alloy were measured with MTS. Split Hopkinson Pressure Bar (SHPB) was used to carry out dynamic compression and to obtain dynamic compression properties. The sample is with the dimension of $\phi 4 \mathrm{~mm} \times 4 \mathrm{~mm}$. Soft recovered cylinders were prepared with standard metallurgical method for SEM observation, with etch solution of $\mathrm{HF}: \mathrm{HNO}_{3}: \mathrm{H}_{2} \mathrm{O}=2: 8: 90$, in volume ratio. For TEM samples, cylindrical samples were cut to $0.3 \mathrm{~mm}$ thickness, followed by mechanical thinning and Ion thinning to the thickness about $30 \mu \mathrm{m}$ and diameter of $3 \mathrm{~mm}$. The acceleration voltage of TEM microscopy is $200 \mathrm{KV}$.

\section{Experimental results and discussions}

\subsection{Static mechanical properties of Ti-5553 alloy}

Static mechanical properties of Ti-5553 alloy through different heat treatment procedures are shown in Table 1.

This is an Open Access article distributed under the terms of the Creative Commons Attribution License 4.0, which permits unrestricted use, distribution, and reproduction in any medium, provided the original work is properly cited. 
Table 1. Static mechanical properties of Ti-5553 alloy with different microstructures.

\begin{tabular}{|l|l|l|l|l|}
\hline $\begin{array}{l}\text { Microstru- } \\
\text { cture }\end{array}$ & $\begin{array}{l}\text { Tensile } \\
\text { strength } \\
\text { (MPa) }\end{array}$ & $\begin{array}{l}\text { Compres- } \\
\text { sive } \\
\text { strength } \\
\text { (MPa) }\end{array}$ & $\begin{array}{l}\text { Reduction } \\
\text { of area } \\
\text { section } \\
(\%)\end{array}$ & $\begin{array}{l}\text { Elonga- } \\
\text { tion } \\
(\%)\end{array}$ \\
\hline $\begin{array}{l}\text { Bimodal } \\
\text { structure }\end{array}$ & 1200 & 1670 & 23 & 7.0 \\
\hline $\begin{array}{l}\text { Widmann- } \\
\text { statten } \\
\text { structure }\end{array}$ & 1265 & 1670 & 6 & 2.5 \\
\hline
\end{tabular}
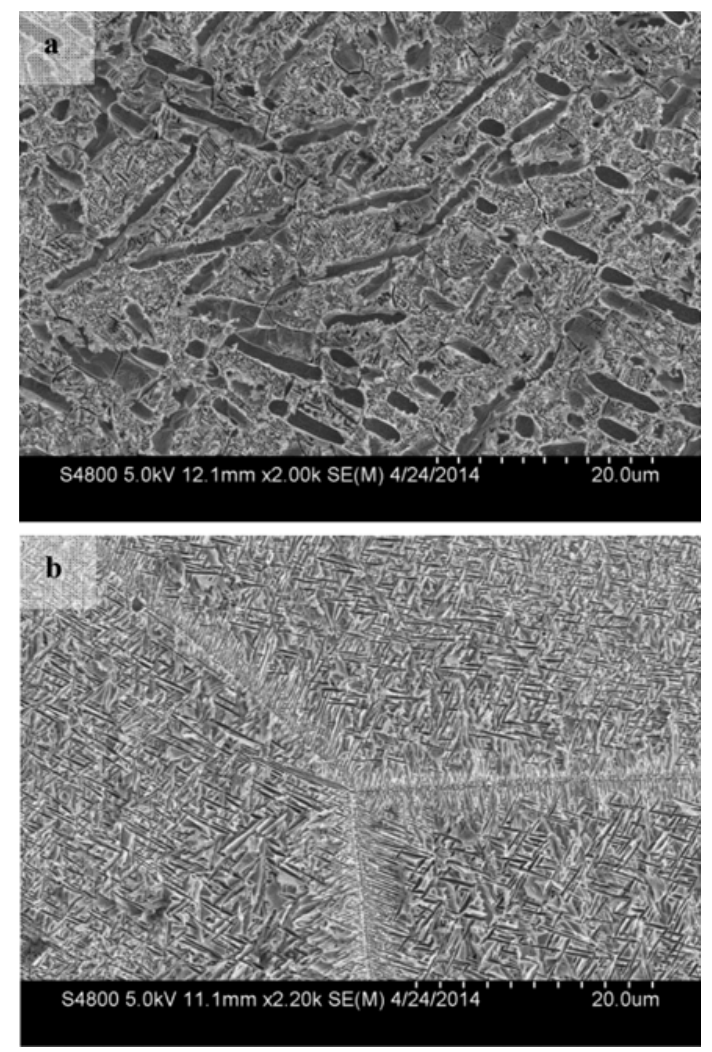

Figure 1. SEM observation of Ti-5553 alloy (a) TL Bimodal microstructure (b) TA Widmannstatten microstructure.

It can be seen that the alloy with Bimodal $\alpha+\beta$ phase exhibit relatively good combination of high tensile strength, compression strength and good ductility. The alloy with Widmannstatten microstructure has relatively higher tensile strength, same compression strength, very low ductility.

The microstructures of Ti-5553 alloy are shown in Fig. 1. Different solid solution temperatures induce various $\alpha+\beta$ phase microstructure contents. For TL Bimodal microstructure, it includes $\alpha_{p}+\alpha_{s}+\beta$, i.e. primary alpha, secondary alpha and beta phases, with primary alpha located discontinue in the beta matrix. For TA Widmannstatten microstructure, it has clear grain boundary and includes $\alpha_{s}+\beta$, i.e. secondary alpha and beta phases. There are more and finer needle second alpha phases and no primary alpha phase in TA microstructure. Therefore, with increasing solid solution temperature, matrix beta phase transforms more to the primary alpha
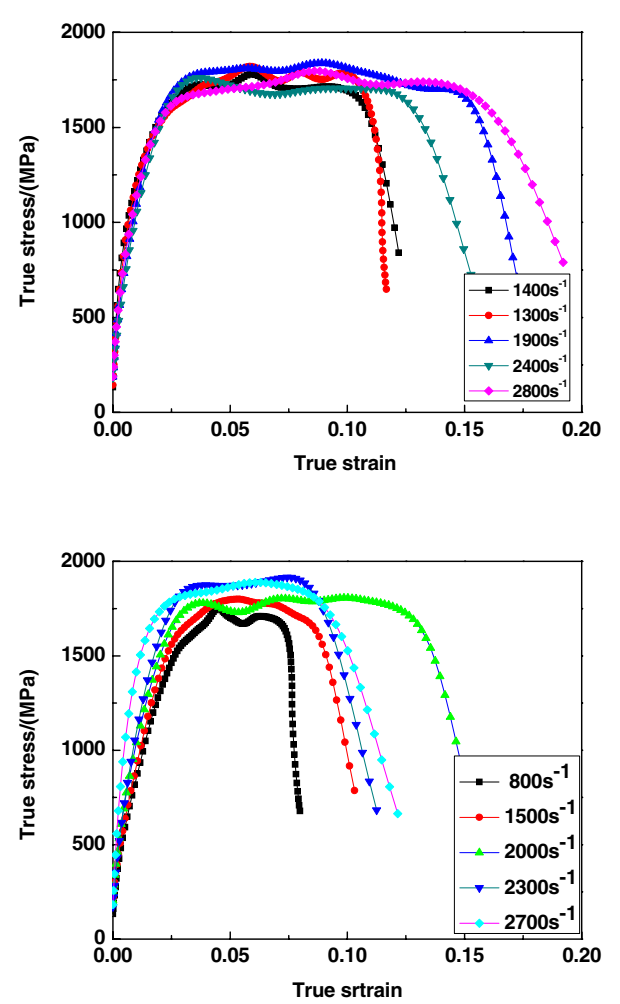

Figure 2. True strain-true stress curves of Ti-5553 alloy under different high strain rates (a) TL Bimodal microstructure (b) TA Widmannstatten microstructure.

and then to secondary alpha phase, the content of primary alpha phase decreases.

\subsection{Dynamic mechanical properties with SHPB}

The true strain-true stress curves of Ti-5553 alloy are shown in Fig. 2. For the alloy with both microstructures, the stresses developing with strains exhibit similar trend. The stresses increase quickly with the increasing strain, with no obvious yield point, keep steady till stress collapse. Also, the strain rate hardening and strain hardening effects balance with thermal softening effect, therefore the plastic deformation stages keep steady, with the maximum compression strength is about $1800 \mathrm{MPa}$ for TL and about $1900 \mathrm{MPa}$ for TA. In the strain rates ranging from $800 \mathrm{~s}^{-1}$ to $2700 \mathrm{~s}^{-1}$, the stress increase more obviously for TA Widmannstatten microstructure alloy, compared with that TL Bimodal microstructure, which indicate the more obvious strain rate hardening effect for TA alloy. This is possibly because TA microstructure has similar high strength, but lower ductility, compared with TL alloy. Meanwhile the secondary alpha phase in TA Widmannstatten microstructure is more and finer than that in TL Bimodal microstructure.

\subsection{Microstructure evolutions}

\subsubsection{Adiabatic shear band under SHPB compression}

The microstructure evolutions are shown in Fig. 3 and Fig. 4. For TL Bimodal alloy, the critical strain rate for 

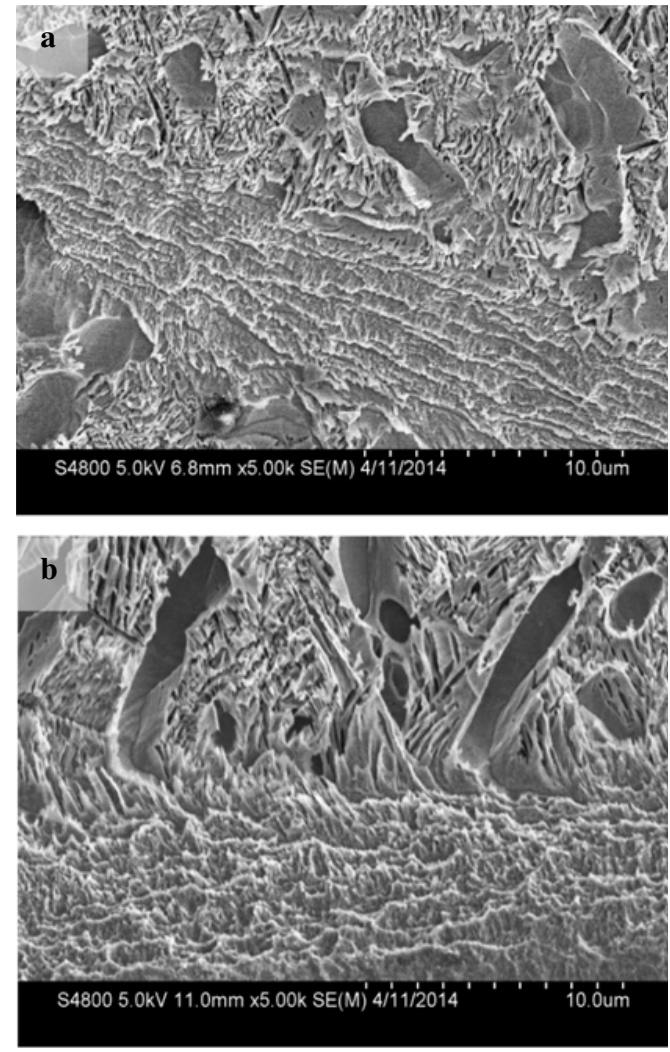

Figure 3. Adiabatic shear band of TL Bimodal alloy (a) ASB under strain rates of $1500 \mathrm{~s}^{-1}$; (b) ASB under strain rates of $2600 \mathrm{~s}^{-1}$.

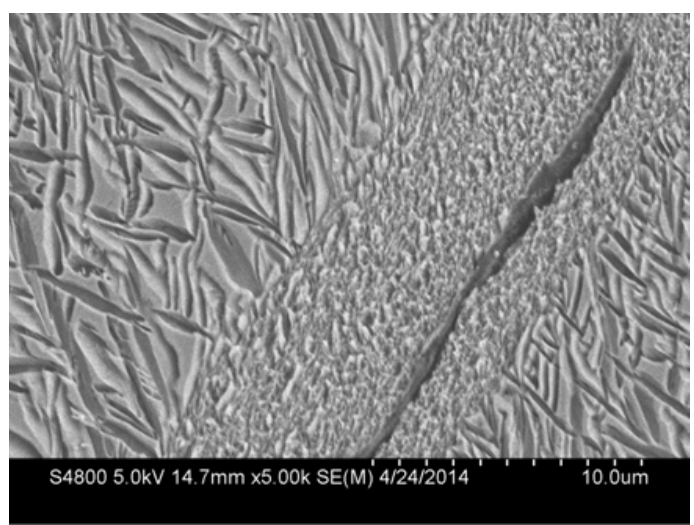

Figure 4. Adiabatic shear band of TA Widmannstatten microstructure alloy under strain rate of $1500 \mathrm{~s}^{-1}$.

adiabatic shear band nucleation is about $1500 \mathrm{~s}^{-1}$. TL cylinder fractures under strain rate of $2600 \mathrm{~s}^{-1}$, along with transformed shear band which develop from deformed to transformed shear band with the increasing strain rate. For TA Widmannstatten alloy, the critical strain rate for ASB nucleation is $1000 \mathrm{~s}^{-1}$, and the sample fracture occurs under $1500 \mathrm{~s}^{-1}$, with wider transformed shear band occur, comparing with TL alloy. This indicates that for Ti-5553 alloy, even with both alpha and beta phases, TA alloy which is solid solution treated at temperature higher than phase transformation exhibits more sensitivity to adiabatic shear localization, lower critical strain rate for ASB nucleation.

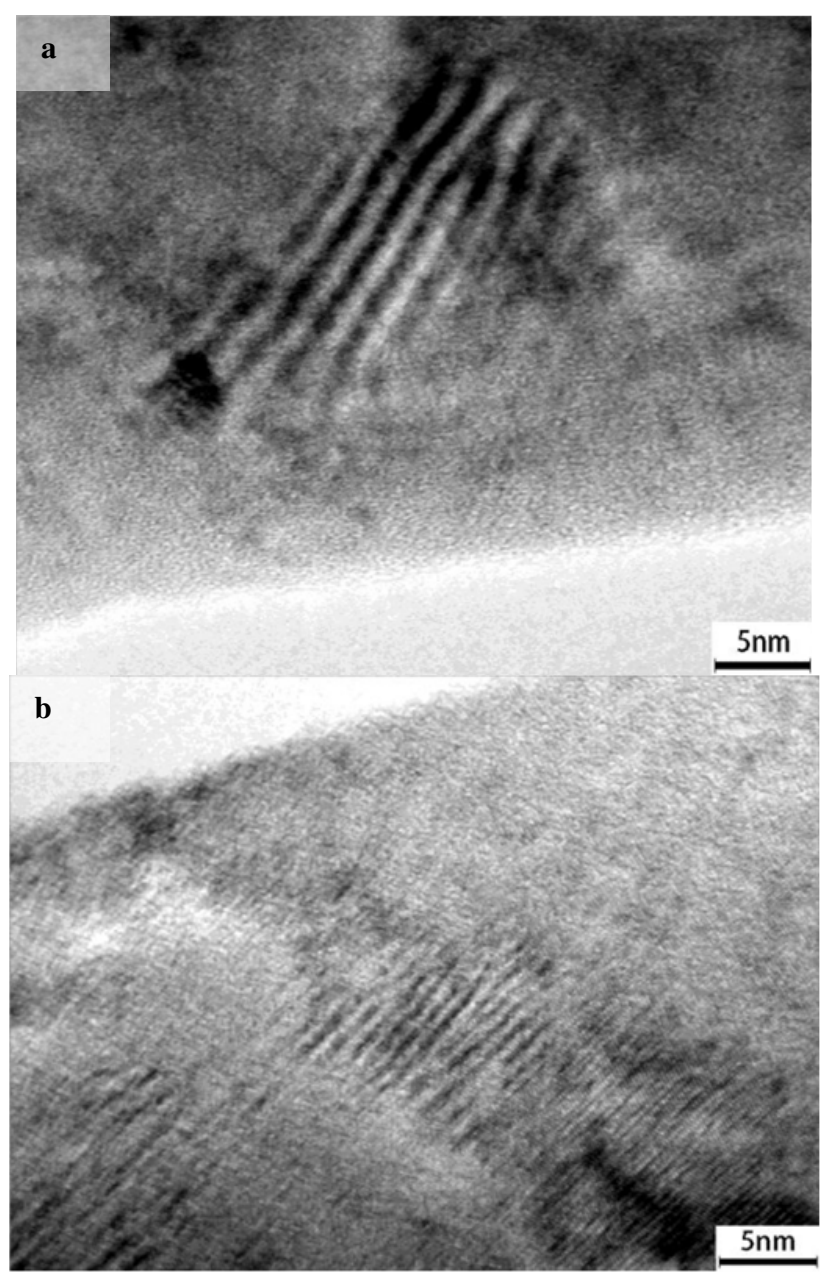

Figure 5. TEM observation of Ti-5553 alloy under strain rate of $1500 \mathrm{~s}^{-1}$ (a) TL Bimodal microstructure; (b) TA Widmannstatten microstructure.

The possible reason for the different critical strain rate for ASB nucleation is the content of primary and second alpha phases. With the increasing solid solution temperature from $770^{\circ} \mathrm{C}$ for $\mathrm{TL}$ alloy to $850{ }^{\circ} \mathrm{C}$ for TA alloy, primary alpha phase decrease or even disappear, more secondary alpha phase produce. The needle-shape secondary alpha phase is relatively difficult to deform, compared with ellipse-shape primary alpha phase, which induce easily uneven plastic deformation or localized deformation under high strain rate loading. The uneven plastic deformation corresponds to the adiabatic shear banding nucleation and development.

\subsubsection{Shock-induced phase transformation under SHPB compression}

In SEM observation, only microstructure evolution of ASBs could be observed. However, although no obvious transformed phase could be observed by means of SEM, shock-induced martensite (SIM) transformation could be found in TEM, as shown in Fig. 5. The transformation product of plate-shape $\alpha^{\prime \prime}$ phase exists [9], which is different from the secondary $\alpha$ phase observed in SEM. The plate width of $\alpha^{\prime \prime}$ phase in TA Widmannstatten alloy 
is finer than that in TL Bimodal alloy. Also, the density number of dislocation lines served as the nuclei sites for $\alpha^{\prime \prime}$ phase is much more in TA alloy than in TL alloy, which means more $\alpha^{\prime \prime}$ SIM phase possible occur in TA alloy. These two microstructure characteristics contribute to the obvious strain rate hardening effect in TA Widmannstatten alloy, compared with TL Bimodal alloy.

The occurrence of SIM phase in near-beta titanium alloy may also influences the nucleation of ASB to some extents. However, in this paper, more SIM phase occur TA Widmannstatten alloy, which is also more sensitive to ASB nucleation. This result is opposite to SIM transformation happened in pure beta phase in TB10 alloy, where SIM phase transformation suppress the nucleation of ASB [9]. The possible reason is that in this study, the microstructure combine both $\alpha$ and $\beta$ phases. Although $\beta$ phase is meta-stable and easy to transform to $\alpha^{\prime \prime}$ phase under shock loading, but the primary $\alpha$ phase restrain the SIM transformation. In TA alloy, as almost no primary $\alpha$ phase exist, thus has no restrain effect for occurrence of SIM phase transformation. Therefore, more SIM phase was observed in TA alloy. At the meantime, the alloy has lower critical strain rate for ASB nucleation. So, it is the alpha/beta phases microstructure that concerns the main difference from the pure beta phase in metastable titanium alloy.

\section{Conclusions}

In summary, we have found that Ti-5553 alloy with Widmannstatten microstructure exhibit more obvious strain rate hardening effect, lower critical strain rate for ASB nucleation, compared with the alloy with Bimodal microstructures. Under dynamic compression, more shock-induced martensite (SIM) beta to alpha" transformation occurs in the alloy with Widmannstatten microstructure compared with the alloy with Bimodal microstructures, which is related with the original alpha/beta microstructures.

\section{References}

[1] R Panza-Giosa. Sc. thesis. McMaster University \& University of Toronto (2009)

[2] B A Welk. Sc. Thesis, Ohio State University, (2010).

[3] J Huang, Z R Wang, K M Xue. Mater. Sci. Eng. A, $528(29-30)(2011)$

[4] N G Jones, et al. Acta Materialia, 57(13) (2009)

[5] S K Kar, et al. Materials Characterization, 81 (2013)

[6] F Xue, et al. Chinese J Nonferrous metals, 20(1) (2010)

[7] Y Ren, et al. Mater. Sci. Eng A, 562 (2013)

[8] E Aeby-Gautier, et al. J. Alloy and Compounds, 577 (2013)

[9] Z P You, et al. Chinese J. Rare Metal, 35(2) 2011

[10] Duvall et al. Shock-induced phase transitions in solids: propagation of shock waves in solids, ASME, 17 (1976)

[11] Q Y Sun, et al. J. Mater. Sci., 37 (12) (2002)

[12] X Xu, L Wang, et al. SEM Fall Conference \& International Symposium on Intensive Loading and Its Effects (2014) 